\title{
Künstliche Intelligenz
}

\section{Schnellere photodynamische Simulationen}

Künstliche neuronale Netze beschleunigen die Simulation von molekularen Reaktionen.

In ihrer Studie [1] zeigen die Forscher um Dr. Philipp Marquetand von der Fakultät für Chemie der Universität Wien, wie künstliche Intelligenz effiziente photodynamische Simulationen ermöglicht.

Um photoinduzierte Prozesse, wie sie etwa im Rahmen der visuellen Wahrnehmung oder der Entstehung von Hautkrebs ablaufen, zu verstehen, muss die Bewegung der Moleküle unter Einwirkung von UV-Licht verstanden werden.

Mit bisherigen Verfahren konnten nur die photoinduzierten Prozesse im Bereich von Pikosekunden bei Rechenzeiten von mehreren Monaten vorhergesagt werden. Das neue Verfahren ermöglicht Simulationen über längere
Zeiträume, im Bereich einer Nanosekunde, bei wesentlich weniger Rechenzeit. Bei ihrem Ansatz verwenden die Forscher künstliche neuronale Netze.

Im Rahmen der Studie führten die Forscher photodynamische Simulationen von Methylenimmoniumkation, einem Bausteines des Moleküls Retinal, das unsere Sehprozesse ermöglicht, durch. Nach zwei Monaten Rechenzeit konnte die Reaktion im Zeitraum von einer Nanosekunde abgebildet werden. Auf Basis bisheriger Verfahren hätte die Simulation zirka 19 Jahre gedauert.

Ein Großteil der photochemischen Prozesse läuft im Bereich von Nanosekunden ab: „Das von uns präsentierte Vorgehen kann man auf verschiedenste kleinere Moleküle - darunter
DNA-Bausteine und Aminosäuren anwenden", so Marquetand. In einem nächsten Schritt wollen die Forscher ihr Verfahren nutzen, um Tyrosin näher zu untersuchen. Es besteht der Verdacht, dass die Schädigung von Tyrosin unter Einfluss von Licht Blindheit und Hautalterung begünstigt.

\section{Literatur}

1. Gastegger M et al (2019) Machine learning enables long time scale molecular photo-

dynamics simulations. Chem Sci. https://doi.org/10.1039/C9SC01742A

\section{hautnah 2019 $\cdot 18: 121$}

https://doi.org/10.1007/s12326-019-

00349-7

(c) Springer-Verlag GmbH Austria, ein Teil von Springer Nature 2019
Quelle: Presseaussendung der medizinischen Universität Wien

Hier steht eine Anzeige. 